\title{
Using Digital Mind Map in teaching Arabic
}

\section{Abdelshafi Ahmed Sayed, Abdelraheem Abbas Amin and Shefaa Mohamed Hussain Mohahammed}

Faculty of Education, South Valley University

\section{Abstract}

Based on the Self Observation \& the Previous Studies' Results \& the Study of the Actual The recent study investigated the effectiveness of using digital mind map on developing some creative writing and reading skills of Arabic majors' at faculty of Education. Research group were (30) male and female students. The study used the semi-experimental approach (pre-post one group design) because the study presented a new treatment which students didn't study before. Two lists of creative reading and writing skills needed to be developed were prepared. The researcher prepared then two units using digital mind map and creative reading and writing skills. The research tools were applied on the research group. Results indicated that there were significant statistic differences between means scores of the study group in favor of posttest. This assured the effectiveness of using digital mid map on developing creative reading and writing skills of Arabic majors at faculty of Education. The study recommended the necessity of applying the latest technology in teaching Arabic in different school stages.

Citation: Sayed et.al., prepare a program in the Islamic culture based on self-regulated learning for Developing some religious concepts and tourism attitudes of Faculty of Tourism and Hotels Students. SVU-Journal of abstract 2019, Vol.1: pp9 (retrieved from the Journal of Educational Sciences; 2018, No.34; pp89).

Copyright: Publisher South Valley University. This is an open access article distributed under the terms of the creative common attribution license, which permits unrestricted use, distribution and reproduction in any medium provided the original author and source are created. 